\title{
Senior medical student attitudes towards patient communication and their development across the clinical elective year - A Q- methodology study
}

\author{
Kristina Schick $^{1}$, Martin Gartmeier ${ }^{1}$ \& Pascal O. Berberat ${ }^{1}$ \\ ${ }^{1}$ Technical University Munich, TUM School of Medicine, TUM Medical Education Center, Germany \\ Article received 4 November 2019 / Article revised 2 December 2020 / Accepted 5 December / Available online 13 January \\ 2021
}

\begin{abstract}
To be proficient in communicating with patients, physicians need specified knowledge, skills and attitudes. Until now, medical educators have mostly focused on undergraduate students' communication knowledge and skills in training and assessment. Attitudes towards communication with patients have been researched less frequently, but it is plausible that they also influence physicians' behaviours in many ways. The present study investigates the communication-focused attitudes of senior medical students and their development through the clinical elective year using an innovative approach based on Q-methodology. We conducted a Q-methodology study using statements from the Kalamazoo Communication Skills Assessment Form. A total of 47 finalyear medical students documented their attitudes towards communication by sorting these statements in regard to their importance into a normal distribution grid in medical interviews. Our innovative approach included three time points during the elective year at which these statements were sorted, with only a slight decrease of participants. We applied a $Q$-factor analysis and found three attitude profiles that were structurally stable over time. Attitude profile \#1 focused on providing information and fostering shared decision making; profile \#2 focused on the patients' concerns and emotions while meeting the patients' demands for sufficient information. Finally, the focus of attitude profile \#3 was on using appropriate conversation techniques to structure communication and gather sufficient information. Overall, the respondents assigned increasing importance to building good relationships and making shared decisions with patients over time. Statements about structuring conversations and communication techniques were evaluated as less important by the end of the clinical elective year.
\end{abstract}

Keywords: Communication competence; attitudes; Q-methodology; longitudinal study. 


\section{Introduction}

For most physicians, communication with patients is a frequent and important aspect of their daily clinical work. It has been estimated that physicians engage in around 150,000 to 200,000 patient conversations during their careers (Fallowfield et al., 2002). Moreover, the importance of good communication has been empirically demonstrated, for example, through its potential to improve doctor-patient relationships, facilitate patient compliance and positively influence physicians' wellbeing (Epstein \& Street, 2011; Ha et al., 2010; Levinson et al., 2010). Consequently, medical education researchers have frequently investigated the question of how communication skills can be improved through didactic interventions (Kurtz et al., 2016; Rider \& Nawotniak, 2010). We adopt a complementary perspective in the present study, with our research question seeking to address how young physicians' attitudes towards communication develop over a one-year period of practical clinical work early in their career (i.e., during their clinical electives). We advance three strategies to substantiate the innovative character of this research question and our approach to answering it. Attitudes are an important yet not well researched aspect of a physician's ability to communicate with patients. In drawing upon Q-methodology, we also employ an innovative methodological approach to measure attitudes towards communicative behaviour in doctor-patient dialogues. Moreover, we focus on informal learning about communication in workplace settings as an often-neglected learning strategy. In approaching the subject in this way, we valuably amend the existing literature, which puts a strong emphasis on the efficacy of formal learning in acquiring communication skills. We adopt a longitudinal perspective comprising three measurements, which is an innovative approach in research using Qmethodology. In doing so, we are able to provide a detailed, empirically based account of the dynamics involved in young physicians' attitudes towards communication across a period characterised by informal learning in a novel work environment. In elaborating on these points in the following, we will further illustrate the innovative character of the present study.

\subsection{Attitudes towards physician-patient communication}

Currently, much research on physician-patient communication focuses on the concept of communication skills (e.g., Kurtz et al., 2016). Communication skills are conceptualised as concrete behaviours (e.g., listening attentively to a patient's statements or negotiating an agenda with a patient), which - if appropriately applied in communication with patients - are elements of a successful physician-patient encounter. In one particular model, Rider (2010) describes a number of essential skills, including opening the conversation, gathering information and fostering shared decision making. Opening a conversation involves a warm welcome, after which an agenda upon which the patient and the doctor could mutually agree is set, which allows the patient to present their concerns without interruption (Rider, 2010). Gathering information entails questioning techniques, history taking and consideration of the possible physical and psychical aspects of the complaints and illness. Gathering information is followed by finding a comprehensive solution due to the concept of shared decision making (Loh \& Simon, 2009). Shared decision making consists of a mutual agreement on the diagnoses and treatment plans to develop a decision tailored to the patient (Loh \& Simon, 2009). An alternative conceptual approach is to think of communication as a professional competence (Epstein \& Hundert, 2002; Mehay \& Burns, 2009). The idea here is that physicians manage to integrate different personal resources in order to perform competently in professional situations. With regard to communication with patients, such resources are skills (as described above), knowledge (of appropriate communication techniques as well as domain-specific, biomedical knowledge) and attitudes towards communication (e.g., seeing it as an essential part of any medical treatment; Blömeke et al., 2015; Hartig, 2008; Schick et al, 2019). Because skills are regarded as one aspect of professional competence, these perspectives complement each other. Research on physician-patient communication, however, has focused mainly on the skills aspect, for instance, through behaviour-oriented methods of assessment, such as Objective Structured Clinical Examinations (Epstein, 2007; Kurtz et al., 2016). In order to advance alternative perspectives that contribute to a more holistic understanding of the physician's role as a communicator, 
shedding light on the aspect of attitudes is valuable. Flocke et al. (2002), for instance, distinguished four communication styles of physicians: biopsychosocial, biomedical, person-focused and high physician control (Flocke et al., 2002). These styles differ in the degrees of focus placed on psychosocial dimensions and the patient's disease and are related to the attitude patterns described by Roter et al. (1997). In both studies, inferences about physicians' attitudes were drawn from external observations. We argue that a more direct research approach involving physicians as respondents is just as plausible. In the following, we will elaborate upon the attitude construct and the relationship between attitudes and behaviour.

Research has drawn upon various definitions of attitudes. First, two types of attitudes can be distinguished: (1) general attitudes towards specific targets like physical objects, groups, policies and events, and (2) "attitudes toward performing specific behaviours with respect to an object or target" (Ajzen et al., 2019). Second, some researchers argue that attitudes are stable and difficult to change, while others assume that attitudes can change over time and are influenced by information (Bohner \& Dickel, 2011). These properties apply to both types of attitudes, which include general attitudes and attitudes towards a particular behaviour. In both cases, attitudes are defined as evaluations "of an object of thought" (Bohner \& Dickel, 2011). Such evaluations can be differentiated into three aspects: cognitive, affective and behavioural. The cognitive aspect refers to persuasions about an object. A person can be convinced about positive or negative attributes of the object of thought through the elaboration of information (Haddock \& Maio, 2014). The affective aspect describes emotions and feelings towards the object, and the behavioural aspect refers to behavioural patterns associated with the object (Haddock \& Maio, 2014). An assumption connected to the behavioural aspect is that concrete experiences with the attitude's object can influence attitudes and lead to attitude change (Bohner \& Dickel, 2011). Our study focuses on attitudes towards behaviour as described in the theory of planned behaviour by Ajzen (1991). This theory poses that behaviour is influenced by intention, which is itself influenced by attitudes towards behaviour, subjective norms and perceived behavioural control. Finally, these three aspects are influenced by beliefs. Beliefs are an individual's convictions regarding the positive or negative consequences of certain behaviours. The conglomerate of positive and negative contributions results in either positive (if positive convictions outweigh negative ones) or negative attitudes (if vice versa) towards the behaviour (Ajzen et al., 2019). Empirical studies have shown that there is a medium relationship between behaviour-related attitudes and actual behaviour (Ajzen et al., 2019). These studies assume that the more precise the measurement of the behaviour-related attitude, the more the attitude can be said to predict the behaviour.

Other different models are helpful in explaining the relationship between attitudes and behaviour, the most relevant one being the MODE model. In this model, two attitude-to-behaviour processes are described: the spontaneous and the deliberative processes (Ajzen et al., 2019). The decision of which process to activate depends on the motivation and the opportunity to elaborate on information. If the motivation is high and the opportunity to elaborate on information is afforded, the deliberative process will be activated. The deliberative process activates a particular attitude based upon an individual act in the given situation. According to this idea, a specific behaviour is consistent with an attitude. However, if there is no opportunity to elaborate on information, a spontaneous process will be activated. Whether the behaviour is in accordance with the attitude or not depends on the strength of the attitude. A strong attitude will be activated automatically, and the presented behaviour will be related to the attitude. However, if it is a weak attitude, there is no automatic activation, and the presented behaviour might not be in line with the attitude (Ajzen et al., 2019; Fazio \& Olsen, 2014). A further approach to describe the relationship between attitudes and behaviour is the reflective-impulsive model (Strack \& Deutsch, 2004). This two-process model, comparable to the MODE model, describes a reflective approach and an impulsive approach. The reflective approach contains an elaborate processing of information and a conscious activation of a behaviour. However, the impulsive approach activates behaviour automatically without considering related information (Strack \& Deutsch, 2004). To investigate attitudes towards patient-centred communication, rating scales have frequently been used. One example is a study on whether cancer patients should be told the truth about their disease (Grassi 
et al., 2000; Locatelli et al., 2013). Such studies are valuable in facilitating understanding of how effective interventions can be designed to improve communication.

Established rating scales for assessing physicians' communication-related attitudes are the Communication Skills Attitude Scale and the Patient-Provider Orientation Scale (Krupat et al., 2000; Rees et al., 2002). However, certain biases described in the methods-focused literature apply specifically to attitude-related studies (e.g., social desirability; Cross, 2005; Klooster et al., 2008). For this reason, different research methodologies should be used to mutually compensate for their disadvantages and to achieve a more balanced picture over time. In the present study, we draw upon the Q-methodology (Brown, 1996; Stephenson, 1936; Watts \& Stenner, 2012), which is tailored to study attitudes while being less prone to effects like social desirability and the tendency to the middle or extreme values (Cross, 2005). In a Q-study, participants are asked to order a set of statements about an attitude's object into a normal distribution grid. Therefore, the statements mutually depend upon each other. Qmethodology is an individual-focused method dedicated to identifying attitude patterns shared by groups of respondents. In contrast, factor analysis (also called the R-method) is variables-focused; its purpose is to identify the underlying factors in sets of variables (Cross, 2005; Watts \& Stenner, 2005). The Qmethodology has already been applied in health care research, for example, by Muddiman et al., 2019, who investigated the views of medical trainees about being a good doctor. Across all the attitude profiles described in this study, the participants judged aspects of good conversational and interpersonal skills as an important part of being a good doctor.

\subsection{Informal learning of communication skills in the workplace}

A further innovative aspect of the present study is its focus on how young physicians' attitudes towards communication develop through the processes of workplace learning. Such learning is embedded in daily clinical practice, is not guided by a teacher or instructor (but may be supported by a colleague or supervisor) and often occurs implicitly (Tynjälä, 2008). Workplace learning is one of the most important ways through which young physicians develop their communication styles with patients (Archer et al., 2008; Bombeke et al., 2012; Brown, 2010). In the research on workplace learning, it is common to distinguish between formal, informal and non-formal learning (Eraut, 2000; Tynjälä, 2008). Formal learning takes place "off the job" in a structured course system with a teacher or trainer purposefully striving to improve learners' job-specific skills and/or knowledge (Eraut, 2000; Manuti et al., 2015). In contrast, informal learning often takes place spontaneously in implicit and unplanned ways. The goals and outcomes of informal learning are not officially documented (Kyndt et al., 2009). Nonformal learning combines aspects of formal and informal learning: like informal learning, non-formal learning activities take place in a work environment and are associated with work activities. However, non-formal learning is more organized than informal learning (e.g., through a mentor or coach supporting the learner; Eraut, 2000). Thus, non-formal learning is an individual process and is tailored to the needs of the trainee. Defined learning goals of non-formal learning often focus on practical learning experiences (Eraut, 2000).

Drawing upon these definitions, clinical electives (which are the final step of undergraduate medical education (UME)) are best described as a non-formal learning setting featuring some formal and informal elements. The participants in clinical electives are still regarded as senior medical students (rather than as young physicians); as such, they are still learners. Each student in the clinical electives is assigned a senior physician as a mentor who provides advice, feedback and, if necessary, instruction on the hows and whys of clinical practice. Therefore, the learning is tailored to the needs of the trainee. Giroldi et al. (2017) investigated the work-related conditions that help trainees to improve their clinical communication skills. Beneficial conditions comprise a psychologically safe environment allowing for different approaches to be tried out, opportunities to learn communication from proficient role models (like a mentor) and time to reflect about one's communication practices (Edmondson, 1999; Giroldi et al., 2017). Bombeke et al. (2012) investigated the transfer of skills acquired in communication seminars with simulated patients to a workplace setting with real patient contact. The authors indicated that there 
was an increase in positive attitudes towards develop patient-centred communication skills when combining simulated training with workplace learning. These findings are in line with suggestions by Archer et al. (2008), who emphasised the importance of considering attitudes and their development during medical education.

During their clinical electives, many medical students are confronted with real (and not simulated) patients on a regular basis. It is plausible that while conducting medical interviews for the first time independently, students may experiment with different techniques and strategies and thereby develop their own routines and preferences regarding communication, yet with no relationship to any formal curriculum (Berings et al., 2005). In addition, young medical students often have many opportunities to observe and learn from more experienced physicians as they communicate with patients in the clinical setting. Through observation and imitation, students might adopt specific behaviours. In a qualitative study, Giroldi et al. (2017) have shown that the interaction between the trainee and trainer caused a change of the frame of reference towards communication with patients. If the trainees have positive experiences with these, routines along with attitudes matching the respective behaviours (Bohner \& Dickel, 2011; Haddock \& Maio, 2014) might be established. We therefore assume that such learning has a great impact on the development of communication competence and also influences the respective attitudes of young physicians. Since little evidence exists in this respect, the present study fills a gap in the literature by tracing the development of communication-related attitudes during clinical electives.

\subsection{Logitudinal perspective on the development and change of attitudes}

Finally, we argue that the present study is innovative because it adopts a longitudinal perspective in examining how attitudes towards communication develop. Few empirical studies have pursued such a research focus (Bombeke et al., 2011; Woloschuk et al., 2004), which is disappointing because much medical education research on communication draws upon the implicit assumption that developmental processes occur in this area and that they can be influenced, for instance, through training (Kurtz et al., 2016) or non-formal learning. Insights into the naturally occurring processes of change over time regarding attitudes towards communication would therefore greatly amend this strand of research. Different models exist that describe the development and change of attitudes. One model is the elaboration likelihood model (ELM), which describes the process of elaborating arguments towards an object of thought and (re-)evaluating this object through the consideration of (new) information (Bohner \& Dickel, 2011; Stroebe, 2014). Besides elaborating on (new) information, another two-path model referring to a heuristic approach is the heuristic-systematic model (HSM). The systemic path is comparable with the ELM. Information is elaborated in a complex procedure. The heuristic path refers to simple strategies like trusting experts, empirical statistics or even sympathetic people. People use the holistic approach if they lack the time to evaluate an object in an elaborative way (Stroebe, 2014). A more recent model is the PAST Model (Past Attitudes Are Still There), developed by Petty et al. (2006). In this case, it is assumed that old attitudes are re-evaluated and, if necessary, corrected. The old attitude will be marked as invalid. Furthermore, the theory of cognitive dissonance is one of the most popular with respect to attitude changes. The theory describes the phenomenon in which a person has to be in cognitive consonance between their attitudes and their behaviour. Even if the attitudes are disaccorded with their behaviour or even their expected behaviour, cognitive dissonance emerges. According to the informal learning character of the clinical electives, we assume that the theory of cognitive dissonance is applicable insofar as the students have initial attitudes towards behavioural aspects of doctor-patient communication. At the wards, they will experience different situations and reactions to their behaviour. If this behaviour is contrary to their own attitudes, cognitive dissonance might occur. They have to adjust their attitude or their behaviour to avoid cognitive dissonance (Haddock \& Maio, 2014).

In the present study, we compare senior medical students' attitudes towards communication with patients measured at three points in time: at the beginning, in the middle and at the end of their clinical elective year to investigate the following two research questions: 
(1) Which attitude profiles of senior medical students regarding physician-patient communication can be differentiated at the beginning of the final year of medical school?

(2) How do these attitude profiles develop during the students' clinical electives in the final year of medical school?

Following the suggestions of Watts and Stenner (2005), we will explain the methodological approach used in the present study by (1) starting with a general overview of Q-methodology, (2) describing the Q-set design and its content, and (3) reviewing the participants of our study. We subsequently explain (4) how we administered the Q-sort materials and (5) analysed the collected data. Following the methods section, we present our results. First, the profiles of the first measurement point are presented, followed by the presentation of the profiles' development across the clinical electives. The article concludes by discussing the results based on the research questions and the current state of research in the discussion. Also, the limitations and further research perspectives are addressed in the discussion section.

\section{Methods}

\subsection{General overview of Q-methodology}

William Stephenson introduced Q-methodology as a way to measure attitudes (Stephenson, 1936; Watts \& Stenner, 2005, 2012). This method combines aspects of quantitative and qualitative research and focuses on identifying groups of individuals with specific attitude profiles who are prevalent in larger samples (Brown, 1996). Q-method studies investigate such attitude profiles by means of card-sorting procedures (McHugh et al., 2018; McHugh et al., 2019; Muddiman et al., 2019). The cards show different statements (the Q-set), which respondents sort into a normal distribution grid (cf. Figure 1). Then, the participants judge each statement regarding its importance with respect to a specific criterion. As was mentioned above, this forced-choice procedure minimises certain response biases, such as tendencies towards the middle or one end of a scale (Müller \& Kals, 2004). The different responses were analysed using Q-factor analysis. Its purpose is to differentiate the attitude profiles based on similarities between the collected Q-sorts. The different profiles are narratively described according to how the collected statements are ordered by the respondents (Watts \& Stenner, 2012).

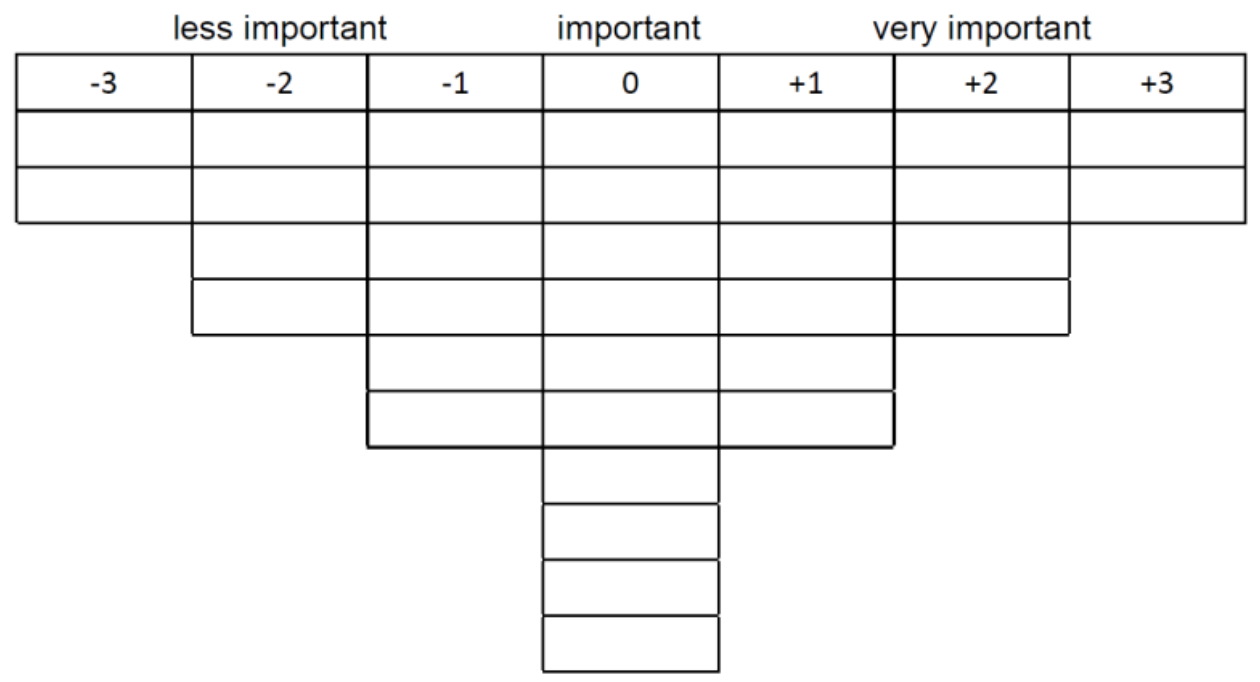

Figure 1. Q-sort grid 


\subsection{Q-set design and content}

The Q-set of our study consisted of the 34 anchor statements (AS) of the German version of the Kalamazoo Communication Skills Assessment Form for students' self-appraisal (KCSAFd-self, cf. Table 2) (Rider, 2010; Schick et al., 2019). In its original use, the global items were assessed by raters, and the corresponding anchor statements were used as reference points for the assessment of the global items. The scale showed good internal consistency (Cronbach's $\alpha=.79$; Schick et al., 2019); it comprehensively describes key communication skills in doctor-patient dialogues and thus meets the requirements for a substantial Q-set. In our study, we used the AS instead of the nine global items because the AS represent concrete behaviours relevant in doctor-patient dialogues. The nine global items were "building interpersonal relationships" (4 AS), "taking the patients' perspectives" (2 AS), "showing empathy" (4 AS), "opening the conversation" (3 AS), "providing closure" (5 AS), "gathering information" (4 AS), "communicating information" (5 AS), "sharing information" (3 AS) and "reaching agreement" (4 AS). The distribution grid (Figure 1) consisted of seven columns ranging from "less important" ( -3 to -1$)$ to "important" $(0)$ and "very important" $(+1$ to +3$)$. The students had to select two items for the categories " $+/-3$ ", four items for the categories " $+/-2$ ", six items for the categories " $+/-1$ " and ten items for the category " 0 ".

\subsection{Participants and study design}

Our target group consisted of senior medical students at the Technical University of Munich in the clinical elective period of their final year in 2017/2018. In Germany, the clinical elective period lasts 48 weeks and is divided into three 16-week terms. Each medical student has to conduct one term each in surgery and internal medicine and can choose where to spend the third term. We introduced our study at the welcome session for the local clinical elective students and invited them to participate. Students were asked to take part in three measurements: in the first week $\left(t_{1}\right)$, after 24 weeks $\left(t_{2}\right)$ and close to the end of their clinical elective period ( $\mathrm{t}_{3}$, after 46 weeks). The sample was a convenience one. Participation was voluntary and rewarded with a book voucher of increasing value after completing the three Q-sorts $\left(t_{1}=15\right.$ EUR; $t 2=30$ EUR; $t 3=60$ EUR $)$. A total of 47 final-year undergraduate medical students participated. This number decreased slightly over time (cf. Table 1). Ten students participated only at $t_{1}$, another student participated at $t_{1}$ and $t_{2}$, and 36 students participated at all three measurement points. During the year, no further students were included in the study. We conducted a chi ${ }^{2}$ test to analyse the group differences between students who only participated in $t_{1}$ with students who participated also at all three measurement points on the basis of their Q-sort profile in $t_{1}$. The chi ${ }^{2}$ test showed no significant difference between the students who participated at all three measurement points and those who only participated in $\mathrm{t}_{1}\left(\chi^{2}(2)=2.137, p=.343\right)$. The ethics committee of the Klinikum rechts der Isar of the Technical University of Munich approved the study (Project number: 482/17 S).

Table 1

Descriptive statistics of sample size

\begin{tabular}{llll}
\hline & $\mathrm{t}_{1}$ & $\mathrm{t}_{2}$ & $\mathrm{t}_{3}$ \\
\hline$N$ & 47 & 37 & 36 \\
Age: $M(S D)$ & $25.98(2.37)$ & $25.92(2.59)$ & $25.94(2.62)$ \\
Female $(\%)$ & 68.10 & 64.90 & 63.90
\end{tabular}

Note. $N=$ sample size; $M=$ mean; $S D=$ standard deviation; $t_{1}=$ at the beginning of the electives; $t_{2}=$ in the middle of the electives; $t_{3}=$ at the end of the electives; 


\subsection{Administering the Q-sort procedure}

We implemented the Q-study using the FlashQ template (Hackert \& Braehler, 2007), which was adapted to our study purposes. The respective hyperlink was distributed to the participants via email at all three measurement times. Each participant received an individual code, which remained stable across the different measurements and allowed matching of the corresponding Q-sorts. The participants were asked the following guiding question when sorting their Q-set: Which aspects do you consider very important / important / less important in conducting a good medical interview with a patient? First, the participants reviewed all statements in random order and pre-sorted them into three columns (from "very important" to "less important"). Then, students were asked to further sort the statements into the normal distribution grid (Figure 1). Finally, we asked the students to justify their choice of the so-called characterising statements $(+/-3)$ in a short open response format.

\subsection{Statistical analyses}

We ran a Q-factor analysis using the R package "Qmethod" (Zabala, 2018). In order to determine the attitude profiles for each time point based on the collected Q-sorts $\left(t_{1-3}\right)$, we conducted the following steps in the analysis:

(1) We considered:

a. the explained variance;

b. eigenvalues (sum squared loading of all Q-sorts on one factor, with EV $\leq 1$ as acceptable);

c. Humphrey's rule, which "states that a factor is significant if the cross-product of its two significant loadings (ignoring the sign) exceeds twice the standard error" (Watts \& Stenner, 2012, p. 107);

d. the amount of included individual Q-sorts;

e. the correlation between the attitude profiles at $t_{1-3}$; and

f. the interpretative content of the profiles to find the most suitable number of profiles for each time point.

(2) The attitude profiles were interpreted qualitatively by identifying so-called characterising, distinguishing and consensus statements. The characterising statements were those at the endpoints of the normal distribution grid labelled with the values " $+/-3$ ". The distinguishing statements significantly differentiated the profiles from each other, whereas the consensus statements represented common statements between profiles. Furthermore, the following categorical scheme was used:

a. We ordered the statements of the Q-set (see 2.2) by the corresponding nine global items of the Kalamazoo Communication Skills Assessment Form (KCSAF) (Table 2).

b. These nine global items were clustered into four categories based on their content: interpersonal relationships and empathy, opening and closure of the conversation, gathering and communicating information, and shared decision making (Table 2).

(3) On the basis of the nine global items, we calculated the means of the Q-values of the respective statements. The mean values of the categories were combined into one curve for each profile (Figure 2).

(4) The individual-to-individual correlations were calculated by using the factor loadings of each respondent's individual Q-sort at the different time points of the particular factor. The higher the correlation, the more similar the individual Q-sorts were at the different time points.

The development of the profiles was analysed using a combined quantitative and qualitative approach:

(1) To estimate the degree of similarity between profiles, we used the number of distinguishing items. In the traditional Q-methodology approach, the decision on how many Q-sorts to extract is based on the number of distinguishing items. A smaller number of distinguishing items indicates greater 
similarity between different Q-sorts. We used this approach to match similar profiles of the three measurement points. The profiles with the lowest number of distinguishing items were matched. For this calculation, we used an adopted version of the "qmethod" R-packages (Zabala, 2018), where we entered the profiles of each measurement point and compared the position of the statements in each profile per measurement point.

(2) We calculated correlations using the factor loadings of the participants in the corresponding profiles at each time point.

(3) We interpreted the similarities and differences between the profiles at the three time points on the basis of the categorical scheme in a qualitative way, as described above. 
$Q$-values of the three profiles at three time points $\left(t_{1}-t_{3}\right)$

Statements

\begin{tabular}{ccccc}
\multicolumn{3}{c}{ Profile \#1 } & Profile \#2 \\
\hline $\mathrm{t}_{1}$ & $\mathrm{t}_{2}$ & $\mathrm{t}_{3}$ & $\mathrm{t}_{1}$ & $\mathrm{t}_{2}$ \\
INTERPERSONAL RELATIONSHIPS AND EMPATHY
\end{tabular}

\section{Building interpersonal relationships}

(1) I greet and show interest in the patient

0

2

0

(11) I use words that show care and concern throughout the interview

(26) I use tone, pace, eye contact, and posture that show care and concern

(27) I respond explicitly to patient statements about ideas and feelings

\section{Taking the patient's perspectives}

(15) I ask about life events, circumstances and other people that might affect the patient's health

(21) I elicit the patient's beliefs, concerns and expectations about illnesses and treatments

\section{Showing empathy}

(7) My demeanour is appropriate to the nature of the conversations

(29) I identify/label/validate the patient's emotional responses

(30) I show compassion and concern

(34) I respond appropriately to the patient's emotional cues

(1)

(1)

2

2

1

1

0

$$
0
$$

0

$-1$

1

\section{3}

2

2

1

$t_{3}$

$\mathrm{t}_{1}$

\begin{tabular}{cc}
\hline Profile \#3 & \\
\hline $\mathrm{t}_{2}$ & $\mathrm{t}_{3}$ \\
\hline
\end{tabular}




$t_{3}$

(2)

$\mathrm{t}_{1}$

\section{OPENING AND CLOSURE OF CONVERSATION}

\section{Opening the conversation}

(4)I allow the patient to complete the opening statement without interruption

(9) I ask, "Is there anything else?" to elicit a full set of concerns

(28) I explain and/or negotiate an agenda for the visit

\section{Providing closure}

(13) I acknowledge the patient and close the interview

(14) I ask if the patient has questions, concerns or other issues

(22) I provide appropriate contact information if interim questions arise

(24) I clarify a future time when progress will again be discussed

(33) I summarise
0

$-1$

$-1$

0

$-3$

0

$-1$
$-1$

$-2$

$-1$

$-2$

1

$-1$

$-1$

$-2$
0

$-2$

1

0

1

$-1$

$-1$

0
0

$-2$

$-1$

$-2$

2

$-1$

$-1$

0

0
$-1$

$-1$

0

$-1$

0

$-1$ $\mathrm{t}_{2}$

$t_{3}$

\section{GATHERING AND COMMUNICATING INFORMATION}

\section{Gathering information}

(6) I address patient statements using open-ended questions

(10) I transition effectively to additional questions

$-2$

$-3$

1

$-1$

$-1$

$-3$

$-3$

0

0

0

$-3$

-2
-2

-

0

0

0

$\begin{array}{ll}-1 & 0 \\ 1 & -2\end{array}$

0

$-1$

(1)

2

2

0
-1
0
-2

0

or add information

(n)

0

0




\begin{tabular}{|c|c|c|c|c|c|c|c|c|c|}
\hline \multirow[t]{2}{*}{ Statements } & \multicolumn{3}{|c|}{ Profile \#1 } & \multicolumn{3}{|c|}{ Profile \#2 } & \multicolumn{3}{|c|}{ Profile \#3 } \\
\hline & $t_{1}$ & $t_{2}$ & $t_{3}$ & $t_{1}$ & $t_{2}$ & $t_{3}$ & $\mathrm{t}_{1}$ & $t_{2}$ & $t_{3}$ \\
\hline $\begin{array}{l}\text { (20) I clarify details as necessary with more specific or } \\
\text { "yes/no" questions }\end{array}$ & -3 & -3 & -3 & -3 & -2 & -2 & 0 & -3 & -1 \\
\hline \multicolumn{10}{|l|}{ Communicating information } \\
\hline (2) I clearly present and explain options for future care & 2 & 2 & 2 & -1 & -1 & -2 & 1 & 1 & 1 \\
\hline $\begin{array}{l}\text { (18) I give enough clear information to empower decision } \\
\text { making }\end{array}$ & 3 & 2 & 3 & 0 & 0 & 0 & 1 & 3 & -1 \\
\hline $\begin{array}{l}\text { (19) I accurately convey the relative seriousness of the } \\
\text { patient's condition }\end{array}$ & 0 & -1 & 0 & -2 & -1 & -3 & -1 & 1 & 1 \\
\hline (23) I clearly convey expected disease courses & 0 & -1 & -1 & -2 & -3 & -3 & -2 & 1 & 0 \\
\hline (32) I take other participating clinicians' inputs into account & 0 & 1 & 0 & -2 & -2 & -1 & -1 & 0 & 0 \\
\hline
\end{tabular}

\section{Sharing information}

(5) I ask if the patient has any more questions

SHARED DECISION MAKING

(12) I explain using words that the patient can understand

(16) I assess the patient's understanding of problems and the desire for more information

\section{Reaching an agreement}

\section{(3) I identify additional resources that are appropriate}

(8) I ask about the acceptability of the diagnostic and/or treatment plans
0

3

1

$-1$

$-2$

0

2

\section{2}

3

2

1

0

0

0

1

0

1 


\begin{tabular}{cc} 
& Profil \\
\hline $\mathrm{t}_{1}$ & \\
-1 &
\end{tabular}

Profile \#1

$\mathrm{t}_{2}$

(25) I include patients in choices and decisions to the extent they desire

(31) I check for mutual understanding of diagnostic and/or treatment plans

2

2

1

Profile \#2

Profile \#3

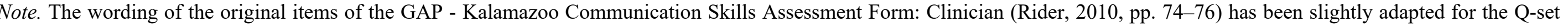
statements. 


\section{Results}

The first research question concerns medical students' attitude profiles regarding physicianpatient communication at the beginning of the final year of medical school. The Q-factor analysis determined a three-factor solution as most suitable for our data. Table 3 presents the quantitative criteria of the two-, three-, and four-factor solutions (for further information, see also Section 2.5). All threefactor solutions provided acceptable quantitative criteria, but the two factor solution included too many Q-sorts per factor. This led to a lower degree of differentiation between the participants. The four-factor solution provided two factors with less than six participants; this outcome did not comply with the recommendations of Watts and Stenner (2012). Therefore, the three-factor solution provided good quantitative and qualitative criteria to interpret the three factors.

For the three-factor solution, the correlations between the profiles were $r=.339$ between profiles 1 and $2, r=.560$ between profiles 1 and 3 , and $r=.306$ between profiles 2 and 3 at $t_{1}$. The three profiles explained $44.46 \%$ of the total variance. In the following sections, we narratively describe the profiles at $\mathrm{t}_{1}$ according to the four categories of interpersonal relationships and empathy, opening and closure of conversation, gathering and communicating information and shared decision making. The three profiles and their development are presented in Figure 2. 
Table 3

Overview of psychometric properties of different factor solutions.

\begin{tabular}{|c|c|c|c|c|c|c|}
\hline $\begin{array}{l}\text { Measurement } \\
\text { point }\end{array}$ & $\begin{array}{l}\text { Number of } \\
\text { factors }\end{array}$ & $\begin{array}{l}\text { Number of } \\
\text { profile }\end{array}$ & $\begin{array}{l}\text { Explained } \\
\text { variance }(\%)\end{array}$ & $\begin{array}{l}\text { Eigenvalues } \\
(>1)\end{array}$ & $\begin{array}{l}\text { Humphrey's } \\
\text { rule }(\geq .34)\end{array}$ & $\begin{array}{l}\text { Number of } \\
\text { loading Q- } \\
\text { sorts }\end{array}$ \\
\hline \multirow[t]{9}{*}{$t_{1}$} & \multirow[t]{2}{*}{2} & 1 & 22.35 & 10.51 & 0.55 & 26 \\
\hline & & 2 & 14.35 & 6.74 & 0.51 & 17 \\
\hline & \multirow[t]{3}{*}{3} & 1 & 18.29 & 8.60 & 0.58 & 16 \\
\hline & & 2 & 16.41 & 7.71 & 0.52 & 7 \\
\hline & & 3 & 9.77 & 4.59 & 0.59 & 10 \\
\hline & \multirow[t]{4}{*}{4} & 1 & 18.10 & 8.51 & 0.55 & 16 \\
\hline & & 2 & 16.35 & 7.68 & 0.67 & 13 \\
\hline & & 3 & 8.23 & 3.87 & 0.58 & 5 \\
\hline & & 4 & 7.44 & 3.49 & 0.45 & 2 \\
\hline \multirow[t]{9}{*}{$t_{2}$} & \multirow[t]{2}{*}{2} & 1 & 23.12 & 8.56 & 0.61 & 19 \\
\hline & & 2 & 16.47 & 6.09 & 0.55 & 14 \\
\hline & \multirow[t]{3}{*}{3} & 1 & 20.29 & 7.51 & 0.54 & 14 \\
\hline & & 2 & 14.49 & 5.36 & 0.42 & 8 \\
\hline & & 3 & 12.09 & 4.47 & 0.52 & 9 \\
\hline & \multirow[t]{4}{*}{4} & 1 & 20.00 & 7.40 & 0.60 & 13 \\
\hline & & 2 & 14.55 & 5.38 & 0.54 & 9 \\
\hline & & 3 & 9.50 & 3.52 & 0.48 & 7 \\
\hline & & 4 & 9.45 & 3.50 & 0.50 & 5 \\
\hline \multirow[t]{9}{*}{$t_{3}$} & \multirow[t]{2}{*}{2} & 1 & 26.02 & 9.37 & 0.62 & 22 \\
\hline & & 2 & 15.16 & 5.46 & 0.70 & 9 \\
\hline & \multirow[t]{3}{*}{3} & 1 & 22.00 & 7.91 & 0.62 & 16 \\
\hline & & 2 & 15.04 & 5.41 & 0.69 & 7 \\
\hline & & 3 & 11.97 & 4.31 & 0.53 & 10 \\
\hline & \multirow[t]{4}{*}{4} & 1 & 21.47 & 7.73 & 0.50 & 14 \\
\hline & & 2 & 14.17 & 5.10 & 0.70 & 4 \\
\hline & & 3 & 10.49 & 3.77 & 0.45 & 5 \\
\hline & & 4 & 9.04 & 3.25 & 0.48 & 5 \\
\hline
\end{tabular}




\section{Profile \#1}

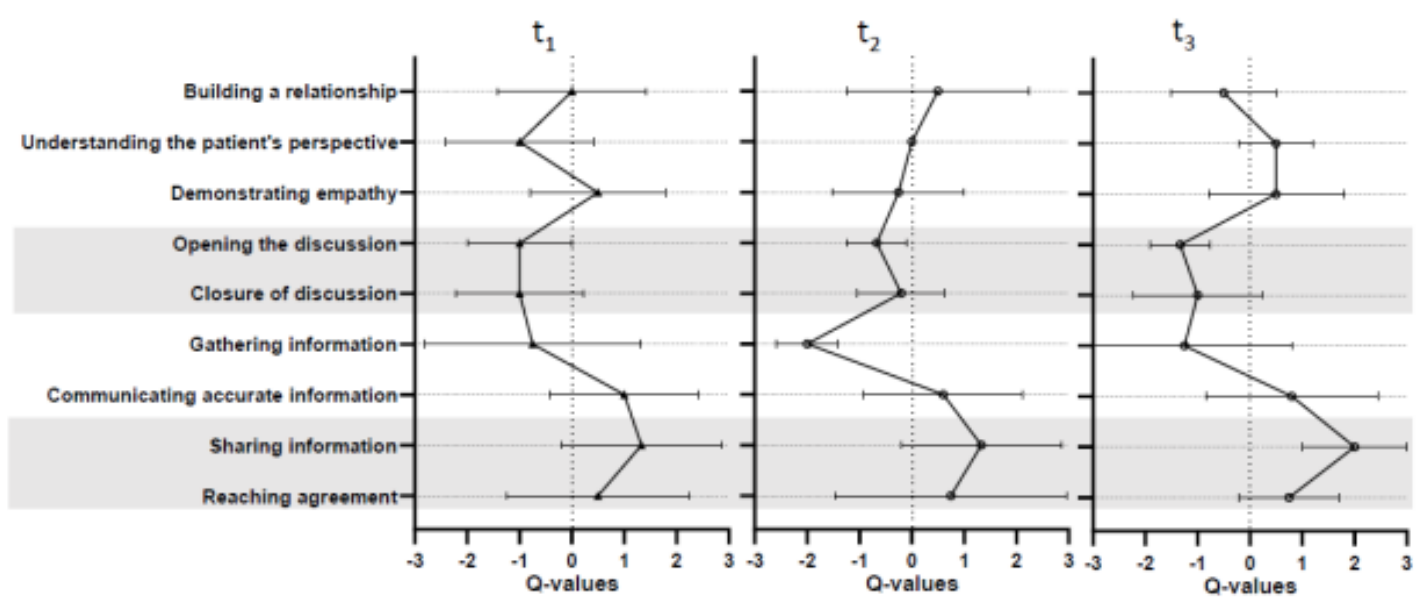

\section{Profile \#2}
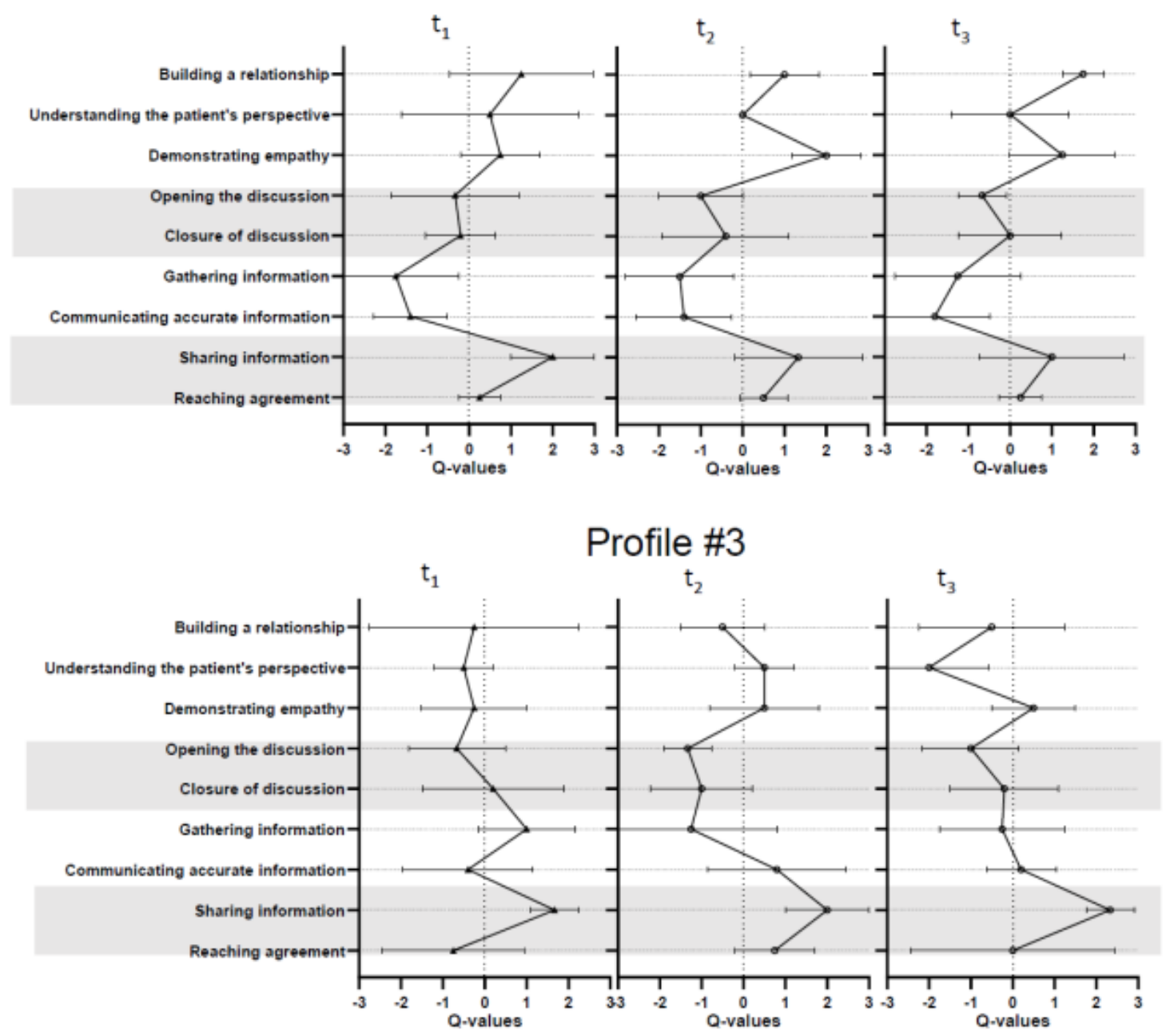

16 | F L R 

values

Figure 2. Profile curves of all three time points based on means and standard deviations of Q-

\subsection{Profiles at the beginning of the final year of medical school $\left(t_{1}\right)$}

Table 4

Distribution of students based on attitude profiles at all three measurement points

\begin{tabular}{llll}
\hline Attitude profile & $\begin{array}{l}\text { Measurement } \\
\text { point }\end{array}$ & $N$ (female) & $\begin{array}{l}\text { Age: } M(S D) \text { in } \\
\text { years }\end{array}$ \\
\hline 1 & $\mathrm{t}_{1}$ & $19(12)$ & $25.95(2.09)$ \\
& $\mathrm{t}_{2}$ & $14(10)$ & $26.20(2.93)$ \\
& $\mathrm{t}_{3}$ & $16(9)$ & $25.38(1.76)$ \\
& $\mathrm{t}_{1}$ & $14(11)$ & $25.36(1.99)$ \\
& $\mathrm{t}_{2}$ & $8(6)$ & $26.00(3.00)$ \\
& $\mathrm{t}_{3}$ & $9(7)$ & $25.88(2.75)$ \\
& $\mathrm{t}_{1}$ & $9(4)$ & $26.00(2.67)$ \\
& $\mathrm{t}_{2}$ & $11(6)$ & $25.73(2.33)$ \\
& $\mathrm{t}_{3}$ & $9(6)$ & $27.56(3.43)$ \\
\hline
\end{tabular}

Note. $N=$ number of participants; $M=$ mean; $S D=$ standard deviation

\subsubsection{Attitude profile \#1: Providing information and fostering shared decision making}

\subsubsection{Interpersonal relationships and empathy}

Respondents in profile \#1 emphasised that the external appearance of the students should be appropriate, but regarded addressing the patient's concerns and needs $(7:+2 ; \mathbf{1 1}:+1 ; \mathbf{2 6}:+1 ; \mathbf{2 9}:-1$; 27: -2$)^{1}$ as less important for demonstrating empathy and building a relationship with the patient. Regarding perspective taking, exploring the patient's concerns and expectations (21: 0) was considered more important than addressing circumstances of the patient's life (15: -2).

\subsubsection{Opening and closure of conversation}

Individuals in profile \#1 found opening and closing the conversation (28: $-2 ; \mathbf{1 3}:-3)$ to be a less important aspect of a good doctor-patient dialogue.

\subsubsection{Gathering and communicating information}

One aspect individuals in this profile found very important was communicating accurate information. They also emphasised the importance of providing sufficient information to the patient and clearly explaining opportunities for diagnostic and therapeutic plans $(\mathbf{1 8}:+3 ; \mathbf{2}+2)$. However, gathering information was rated as less important by the students in this profile. They stressed the importance of clarifying details and summarising during the dialogue $(6:+1 ; 17:+1)$, but regarded appropriate questioning techniques as less important (10: $-2 ; \mathbf{2 0}:-3)$.

\subsubsection{Shared decision making.}

Shared decision making emerged as another important aspect in profile \#1. Sharing information in an understandable way $(\mathbf{1 2}:+3)$ and ensuring that the patients understood the problems $(\mathbf{1 6 :}+1)$ were of high importance in this profile. The students considered the patient's agreement with therapeutic plans $(8:+2 ; 31:+2)$ as very important for a successful consultation. However, further concerns and needs of the patients were regarded as less important; also, to consider or even include the families in reaching agreements played a subordinate role $(3:-1 ; 25:-1)$.

\footnotetext{
${ }^{1}$ (Statement number: Q-value)
} 
3.1.2 Attitude profile \#2: Focusing on the patients' concerns and emotions while meeting their desire for sufficient information

\subsubsection{Interpersonal relationships and empathy}

According to the respondents in profile \#2, the development of a trustful interpersonal relationship is a very important aspect of physician-patient conversations. The students emphasised the importance of responding to the patients' concerns $(1:+2 ; 11:+3)$ and emotions $(\mathbf{3 4}:+1)$. Empathy and compassion also played a very important role in this profile $(\mathbf{3 0}:+2)$. Moreover, the students considered acknowledging the concerns, doubts and sorrows of patients regarding their complaints to be very important $(21:+2)$.

\subsubsection{Opening and closure of conversation}

Opening the conversation was also considered essential by respondents in profile \#2: They rated the importance of "the patient should have the time to tell his or her story without interruption" as high $(\mathbf{2 8}:+1)$. The students also considered the behaviour of closing the conversation by answering open questions as important $(\mathbf{1 4}:+1)$. However, arranging additional appointments seemed less important in profile \#2 (22: $-1 ; 24:-1)$.

\subsubsection{Gathering and communicating information}

Participants in profile \#2 considered gathering information in a structured way using appropriate conversation techniques to be less important $(6:-1 ; 10:-3 ; 17: 0 ; 20:-3)$. Moreover, the students evaluated communicating concrete information about the diseases and their possible progress (2: -1 ; 19: $-2 ; 23:-2)$ as less important.

\subsubsection{Shared decision making}

Sharing information was rated as very important for profile \#2 students. They considered it important to explain information in an understandable way $(\mathbf{1 2}:+3)$ and consider the patient's understanding of the problem and the desire for information $(\mathbf{5}:+2 ; \mathbf{1 6}:+1)$. In comparison to sharing information, reaching agreements played a secondary but still important role. The patient's agreement with the diagnostic and treatment plans was considered to be very important $(\mathbf{8}:+1)$.

3.1.3 Attitude profile \#3: Using appropriate conversation techniques to structure the communication and gather sufficient information

\subsubsection{Interpersonal relationships and empathy}

The respondents in this profile emphasised greeting the patients and showing interest in their concerns $(1:+3)$. However, further aspects of building a good interpersonal relationship seemed to be less important for the profile (27: $-3 ; \mathbf{2 6}:-1)$. The students also ranked empathy and compassion as being less important for a successful conversation with patients (29: -2). Only behaving appropriately was emphasised as very important $(7:+1)$. The students also considered patients' perspectives on the disease to be less important $(\mathbf{1 5}:-1 ; 21: 0)$.

\subsubsection{Opening and closure of conversation}

The behavioural aspects of opening the conversation were assessed to be less important for the students in profile \#3 (9: $-2 ; 28: 0)$. In contrast, behaviours related to closing the conversation were seen to be more important, especially clarifying open questions and summarising at the end of the visit $(14:+3 ; 33:+1)$.

\subsubsection{Gathering and communicating information}

One priority of profile \#3 was gathering information and using appropriate techniques to structure the conversations $(\mathbf{6}:+2 ; \mathbf{1 0}:+2)$. The students' preferences showed that they rated the importance of communicating information about the diagnostics and treatment plans $(\mathbf{1 8}:+1)$ higher than providing information about the severity and progress of the diseases $(19:-1 ; 23:-2)$. 


\subsubsection{Shared decision making}

For sharing information, the students considered the patient's understandings of the offered information to be very important $(\mathbf{5}:+2 ; \mathbf{1 2}:+2 ; \mathbf{1 6}:+1)$. The students found that obtaining the patient's agreement with the treatment had high importance, which matched that of offering enough information for reaching agreements $(\mathbf{8}:+1)$. In contrast, examining the patient's comprehension of the treatment plans (31: -3) was considered less important.

\subsection{Development of attitude profiles across the clinical electives $\left(t_{2}-t_{3}\right)$}

Our second research question was designed to address how the attitude profiles of senior medical students develop during their clinical electives in the final year of medical school. At $t_{2}$ and $t_{3}$, the Q-factor analysis indicated that a three-factor solution was most suitable in this case as well. At $\mathrm{t}_{2}$, the three factors explained $46.87 \%$ of the total variance. At the end of the clinical electives $\left(t_{3}\right)$, the explained variance of the three factors was $48.99 \%$. In the following sections, the development of the profiles is described according to the four categories of interpersonal relationships and empathy, opening and closure of conversation, gathering and communicating information and shared decision making.

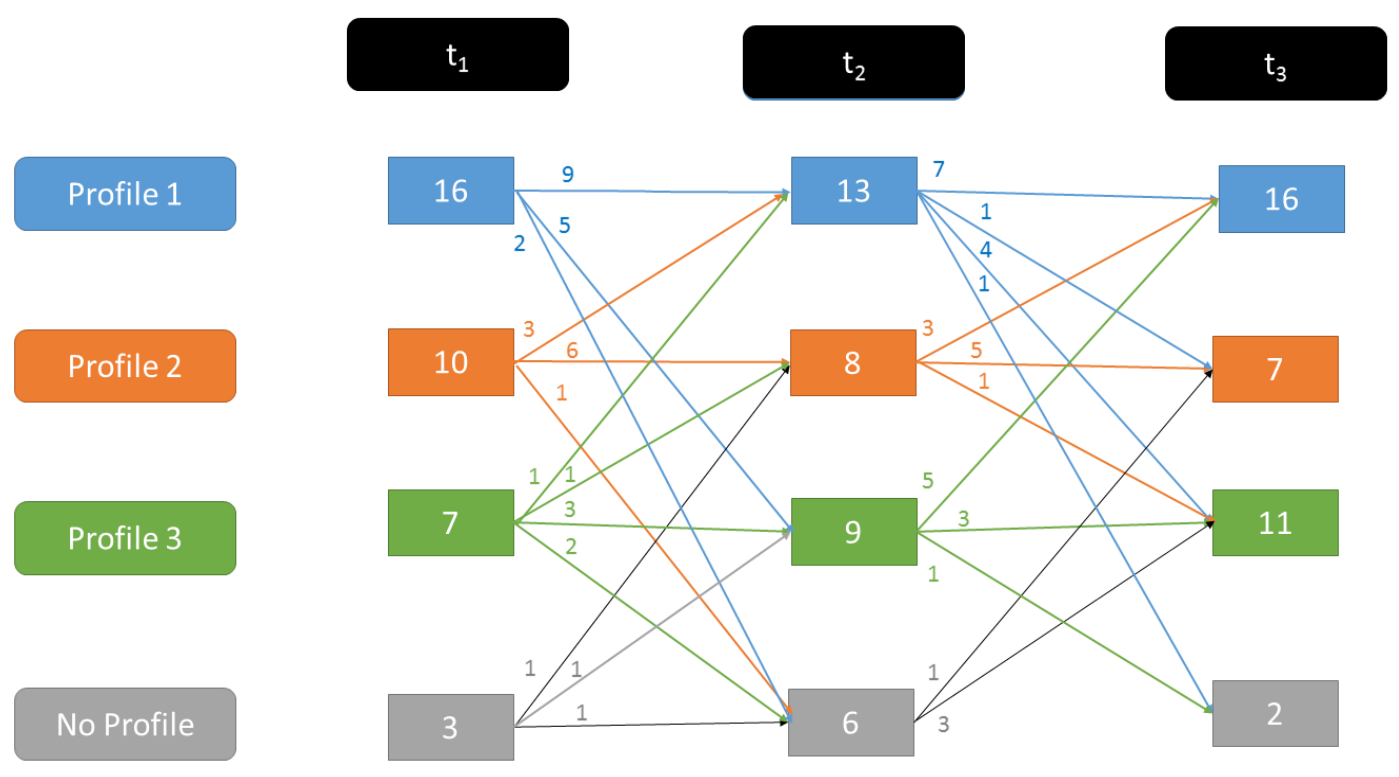

Figure 3. Migration of participants between profiles across the clinical electives 


\subsubsection{Development of attitude profile \#1}

Ten medical students remained in profile \#1 at $t_{2}$ (see Figure 3 ). The average individual-toindividual correlation was $r=.44$ at $\mathrm{t}_{2}$. The correlation of the profile between $\mathrm{t}_{1}$ and $\mathrm{t}_{2}$ was $r=.83$.

Six medical students who represented attitude profile $\# 1$ at $\mathrm{t}_{1}$ and $\mathrm{t}_{2}$ were also clustered in profile $\# 1$ at $t_{3}$. Four students returned to profile $\# 1$ at $t_{3}$ (see Figure 3 ). The individual-to-individual correlation was $\mathrm{r}=.60$ at $\mathrm{t}_{3}$. The correlation between the profiles of $\mathrm{t}_{2}$ and $\mathrm{t}_{3}$ was $r=.85$.

\subsubsection{Interpersonal relationships and empathy}

At $t_{1}$, profile \#1 members agreed with the importance of establishing and maintaining good interpersonal relationships in conversation with patients to a moderate to pronounced degree. As is apparent from Figure 2, the profile \#1 curve shows an overall increase of agreement with the items concerning interpersonal relationships during the electives. In detail, a slight decrease of agreement around the middle and an increase at the end of the clinical electives regarding the demonstration of empathy and compassion $\left(7: t_{1}=+2 ; t_{2}=+1 ; t_{3}=+2\right)^{2}$ and consideration of the patients' emotions and feelings (29: $\left.\mathrm{t}_{1}=-1 ; \mathrm{t}_{2}=-2 ; \mathrm{t}_{3}=-1\right)$ is evident. In particular, the respondents' attitudes towards considering patients' perspectives changed over time. At the end of the clinical electives, agreement with consideration of the living circumstances of patients was higher $\left(15: t_{1}=-2 ; t_{2}=0 ; t_{3}=0\right)$, as was agreement with listening to the patients' concerns and sorrows $\left(\mathbf{2 1}: \mathrm{t}_{1}=0 ; \mathrm{t}_{2}=0 ; \mathrm{t}_{3}=+1\right)$.

\subsubsection{Opening and closure of conversation}

In the eyes of the profile \#1 members, opening and closing the conversation still played a subordinate role in interaction with patients, especially in comparison with communicating information and shared decision making. At $\mathrm{t}_{2}$, the profile members showed higher preferences regarding aspects such as clarifying open questions $\left(14: t_{1}=0 ; t_{2}=+1 ; t_{3}=+1\right)$. However, closing the conversation and saying thanks to the patient were seen as less important throughout the clinical elective year $\left(13: t_{1}=-\right.$ $\left.3 ; \mathrm{t}_{2}=-1 ; \mathrm{t}_{3}=-2\right)$.

\subsubsection{Gathering and communicating information}

Profile \#1 was relatively stable over time regarding agreement with gathering and communicating information. The art of asking received less attention in the middle of the electives, but it again received more attention at the end of the electives $\left(6: t_{1}=+1 ; t_{2}=-2 ; t_{3}=+1\right)$. During their electives, the students considered communicating information about the severity and progress of the disease to be less important (19: $\left.t_{1}=0 ; t_{2}=-1, t_{3}=0 ; 23: t_{1}=0 ; t_{2}=-1 ; t_{3}=-1\right)$. The aspects of clarifying future options of care and communicating enough information to patients remained very important for respondents in this profile $\left(2: t_{1}=+2, t_{2}=+2, t_{3}=+2 ; \mathbf{1 8}: t_{1}=+3, t_{2}=+2, t_{3}=+3\right)$.

\subsubsection{Shared decision making}

The students still considered sharing information to be important for assessing the patient's understanding and need for more information $\left(\mathbf{1 6}: t_{1}=+1 ; t_{2}=+1 ; t_{3}=+2\right)$. This profile also focused on reaching agreements with patients about treatment plans at $t_{2}$ and $t_{3}\left(8: t_{1}=+2, t_{2}=+3, t_{3}=+2\right)$. However, considering the patient's needs increased in importance at the end of the clinical electives (3: $\left.\mathrm{t}_{1}=-1 ; \mathrm{t}_{2}=-2 ; \mathrm{t}_{3}=0\right)$.

\subsubsection{Development of attitude profile \#2}

Six students were already in profile \#2 at $t_{1}$ (see Figure 3 ). The individual-to-individual correlation of the attitude profile was $\mathrm{r}=.49$ at $\mathrm{t}_{2}$. The correlation between the profile at $\mathrm{t}_{1}$ and $\mathrm{t}_{2}$ was $r=.86$.

\footnotetext{
${ }^{2}$ (Statement number: $\mathrm{t}_{1}=\mathrm{Q}$-value; $\mathrm{t}_{2}=\mathrm{Q}$-value; $\mathrm{t}_{3}=\mathrm{Q}$-value $)$
} 
Four students remained in attitude profile \#2 during the clinical electives, and two medical students returned to profile \#2 at $t_{3}$ (see Figure 3 ). The individual-to-individual correlation of the attitude profile was $r=.60$ at $\mathrm{t}_{3}$. The correlation between $\mathrm{t}_{2}$ and $\mathrm{t}_{3}$ was $r=.82$.

\subsubsection{Interpersonal relationships and empathy}

Respondents in this profile put great emphasis on building a trustworthy interpersonal relationship at $t_{1}$; this preference remained stable over time with only slight adjustments. Students considered it important to respond explicitly to the feelings and emotions of the patients $\left(27: t_{1}=-1\right.$; $\left.t_{2}=0 ; t_{3}=+1 ; 29: t_{1}=0 ; t_{2}=+2 ; t_{3}=0\right)$. Overall, respondents regarded considering patients' concerns and sorrows as important, yet seemed to struggle with this evaluation throughout the duration of the electives $\left(21: t_{1}=+2 ; t_{2}=0 ; t_{3}=+1\right)$. A comparable struggle was observable in the attitudes towards an appropriate behaviour regarding the nature of conversations $\left(7: t_{1}=0 ; t_{2}=+3 ; t_{3}=+1\right)$.

\subsubsection{Opening and closure of conversation}

The statements on opening and closing the conversation were estimated to be important throughout all three time points. The respondents regarded summarising the conversation at the end of the visit as increasingly important towards the end of the clinical elective $\left(33: t_{1}=0: t_{2}=0: t_{3}=+2\right)$. However, closing the conversation and expressing gratitude for the patient's confidence were estimated as less important during the clinical electives $\left(13: t_{1}=0 ; t_{2}=-2 ; t_{3}=-1\right)$.

\subsubsection{Gathering and communicating information}

The category gathering and communicating information was judged to be less important at $t_{1}$. This judgement remained stable over time. Some adjustments could be observed, while clarifying details with specific questions decreased in importance $\left(6: t_{1}=-1 ; t_{2}=-1 ; t_{3}=-2\right)$. The students were reluctant to provide specific information about the severity of the disease as early as at $t_{1}$. This assessment became even more pronounced over the course of the electives $\left(19: t_{1}=-2 ; t_{2}=-1 ; t_{3}=-3\right)$.

\subsubsection{Shared decision making}

The students estimated consideration of the patient's understandings to be a less important part of sharing information in $t_{2}$ and $t_{3}$ compared to its high importance at $t_{1}\left(5: t_{1}=2, t_{2}=1, t_{3}=0 ; 16: t_{1}=1\right.$; $\left.t_{2}=0 ; t_{3}=0\right)$. The aspect of reaching agreement remained stable over time. Only the aspect of considering the family's perspective in the agreement process increased in importance during the clinical electives (25: $\left.\mathrm{t}_{1}=0, \mathrm{t}_{2}=0, \mathrm{t}_{3}=+1\right)$.

\subsubsection{Development of attitude profile \#3}

At $t_{2}$, three students were also in profile \#3 at the beginning of the clinical electives (see Figure 3). The individual-to-individual correlation was $r=.53$ at $\mathrm{t}_{2}$. The correlation between the profile in $\mathrm{t}_{1}$ and $\mathrm{t}_{2}$ was $r=.49$.

At $t_{3}$, three medical students who were in profile \#2 at $t_{1}$ had moved to profile \#3 in $t_{3}$. No student stayed in profile \#3 during the clinical electives (see Figure 3). The individual-to-individual correlation was $r=.38$ at $\mathrm{t}_{3}$. The correlation of profile $\# 3$ at $\mathrm{t}_{2}$ and $\mathrm{t}_{3}$ was $r=.46$.

\subsubsection{Interpersonal relationships and empathy}

As was already observed at $t_{1}$, the students in profile \#3 regarded building a trustworthy relationship as quite unimportant across the three measurements $\left(27: t_{1}=-3, t_{2}=-1 ; t_{3}=-3 ; 1: 26: t_{1}=-\right.$ $\left.1, t_{2}=0, t_{3}=0 ; 1: t^{1}=+3, t_{2}=+1, t_{3}=+1\right)$. They also did not agree on the relevance of considering the patients' concerns and sorrows, their living situations, or even their living circumstances at all three time points. The aspect of empathy, however, especially behaving appropriately in a given situation, obtained more concern (29: $\left.\mathrm{t}_{1}=-2, \mathrm{t}_{2}=-1, \mathrm{t}_{3}=0 ; 7: \mathrm{t}_{1}=+1, \mathrm{t}_{2}=+2, \mathrm{t}_{3}=+2\right)$. 


\subsubsection{Opening and closure of conversation}

Profile \#3 showed an emphasis on closing the discussion, while opening the discussion played a secondary role at $t_{1}$. Setting an agenda at the beginning of the visit became more important at $t_{3}(9$ : $\left.t_{1}=-2, t_{2}=-3, t_{3}=0\right)$. Summarising and closing at the end of the conversation seemed to be especially important to the students $\left(33: t_{1}=+1, t_{2}=-2, t_{3}=+1 ; 13: t_{1}=0, t_{2}=-2, t_{3}=+1\right)$. However, clarifying open questions decreased in importance over time (14: $\left.t_{1}=3, t_{2}=0, t_{3}=-1\right)$. Overall, the importance of behavioural aspects related to opening and closing the conversation played a secondary role in this profile.

\subsubsection{Gathering and communicating information}

The profile initially placed great emphasis on gathering information through appropriate conversation techniques. These attitudes were less preferred at $t_{2}$ and $t_{3}\left(\mathbf{1 0}: t_{1}=+2, t_{2}=-2, t_{3}=-1 ; \mathbf{2 0}\right.$ : $\left.t_{1}=0, t_{2}=-3, t_{3}=-1\right)$. Providing appropriate information was considered to be more important during the electives, but showed a decrease at the end of the electives $\left(\mathbf{1 8}: t_{1}=+1 ; t_{2}=+3, t_{3}=-1 ; 23: t_{1}=-2\right.$, $\left.\mathrm{t}_{2}=+1, \mathrm{t}_{3}=0,19: \mathrm{t}_{1}=-1, \mathrm{t}_{2}=+1, \mathrm{t}_{3}=+1\right)$. Overall, agreement with communicating information to patients increased during the clinical electives.

\subsubsection{Shared decision making}

The aspects of sharing information with patients and ensuring patient comprehension were considered to be more important over time compared to the beginning of the electives $\left(12: t_{1}=+2 ; t_{2}=+3\right.$, $\left.t_{3}=+3 ; 16: t_{1}=+1 ; t_{2}=-1, t_{3}=+2\right)$. The students consistently emphasised the importance of the patient's comprehension of the treatment plans $\left(31: t_{1}=-3, t_{2}=0, t_{3}=+3\right)$. In contrast, the families' perspectives were considered to be less important in the decision-making process $\left(\mathbf{2 5}: \mathrm{t}_{1}=-1, \mathrm{t}_{2}=0, \mathrm{t}_{3}=-2\right)$.

\section{Discussion}

Our study investigates attitudes towards different physician behaviours in communications with the patients of senior medical students during their final year of UME.

As our first research question, we examined the attitude profiles of senior medical students at the beginning of their clinical electives in the final year of UME. We identified three different attitude profiles that focused either on communicating information and shared decision making (profile \#1), fostering the doctor-patient relationship (profile \#2) or structuring the conversation and gathering sufficient information (profile \#3). These attitude profiles were developed in accordance with the research findings of Roter et al. (1997), who differentiate five types of physicians using a cluster analysis of questionnaire data into "narrowly biomedical", "expanded biomedical", "biopsychosocial", "psychosocial" and "consumerist" types. Comparable profiles could be identified by Flocke et al. (2002). Instead of five profiles, Flocke et al. (2002) described four different profiles: "biopsychosocial", "biomedical", "person-focused" and "high physician control". Attitude profile \#1 considered informed shared decision making as the most important goal of the doctor-patient visit. This profile is comparable to "biopsychosocial" physicians who mainly elaborate on the concerns and medical conditions of the patients and ensure the patients' understanding their illnesses and possible treatment plans (Flocke et al., 2002; Roter et al., 1997). The second profile focused on establishing a trustworthy interpersonal relationship between the patient and the physician. Flocke et al. (2002) describe a group of physicians as "person-focused" if the physician is focusing more on the patients' personal and emotional conditions than on the diseases themselves. The same profile was identified by Roter et al. (1997), who referred to it as "psychosocial". The physicians in attitude profile \#3 considered behaviours of using appropriate conversation techniques to gather information and communicate accurate information as most important at $t_{1}$. These physicians can be compared to those in the "biomedical" group (Flocke et al., 2002) or the "narrowly biomedical" profile (Roter et al., 1997). This profile includes physicians who concentrate on gathering and communicating information and are less focused on interpersonal issues and fostering an 
appropriate relationship (Flocke et al., 2002; Roter et al., 1997). The profiles "high-physician control" (Flocke et al., 2002) and "consumerist" (Roter et al., 1997) could not be found in our study. The profile "high-physician control" focuses on a doctor-centred communication style. In this view, the doctor leads the conversation and does not respond to the specific needs of patients (Flocke et al., 2002). This approach to communicating with patients is not taught in UME. The predominant focus in UME communication seminars is on a patient-centred approach to communication (Langewitz, 2012). A similar issue could be the reason why we could not find a profile similar to the "consumerist" one proposed by Roter et al. (1997). This profile describes physicians who see themselves as consultants. They provide information to the patient while neglecting (psycho-)social exchange. A main aspect of today's communication training is gathering information to achieve a holistic view of the patient's concerns and needs and providing information to foster shared decision making (Langewitz, 2012).

As our second research question, we investigated the development of medical students' attitude profiles during their clinical electives. First, we interpreted profile changes on the content level, and second, we interpreted migration between profiles. The most stable attitude profile on the content and migration levels was \#2. The medical students in this profile assigned high relevance to building interpersonal relationships and considering patients' concerns regarding their illnesses. Also, an emphasis on statements about shared decision making, gathering and communicating information, and the opening and closure of conversation remained stable over time. Profile \#2 showed the least amount of migration across the clinical electives, which could account for the stability of the profile on the content level. This attitude pattern seemed to represent a successful approach to doctor-patient communication, which remained relatively stable during clinical electives. For the students with attitude profile \#1, empathetic behaviour played an increasingly important role over time. At $t_{1}$, the students judged general statements about empathetic behaviour to be more important, but statements about the individual needs of the patients were considered to be less important. Over time, however, the students judged statements referring to the patients' perspectives about their illnesses and concerns as more important for a successful doctor-patient dialogue. The development of profile \#1 during the clinical electives was characterised by a high degree of migration from profile \#1 to profile \#3 at $t_{2}$ and a constant shift of profile \#1 participants in profile \#3 at $t_{3}$. This could be attributed to the stronger correlation of profiles \#1 and \#3 than the correlation between these two profiles and profile \#2. In other words, the higher similarity of profiles \#1 and \#3 could substantiate the migration between the profiles. It is plausible that the two profiles overlapped at a certain point and that the factor loadings of the students on the two profiles were more similar than the loadings on profile \#2. During the clinical electives, their Q-sorts changed slightly, so that they moved from one profile to the other at $t_{2}$ and $t_{3}$, respectively. Attitude profile \#3 showed the highest degree of change in our study. Participants in this profile rated statements about structuring conversations with the use of appropriate information techniques to be more important at $t_{1}$. Over time, their preferences changed towards considering the provision of information about the illnesses and their treatment options to be more important. Finally, at the end of the electives $\left(t_{3}\right)$, shared decision making was prioritised, as were understanding the patients' perspectives and establishing interpersonal relationships. Nevertheless, the attitudes in this profile were still more physician- than patient-centred.

As mentioned in the introductory part of this text, we conceptualise the clinical electives as a non-formal learning setting. The purpose of the clinical electives is to allow young physicians to transfer the theoretical knowledge acquired during UME into practice. The medical students regularly and responsibly engage in doctor-patient dialogues and (should regularly) receive feedback from their supervisors. This feedback could support students in learning from their experiences. Aside from conducting conversations themselves, the student can just as well observe dialogues between other physicians and their patients. This kind of observation can foster attitude changes as the students learn from role models, which has been described as the heuristic path in the HSM (Stroebe, 2014). Through reflection (i.e., after a working day), attitudes could change with the elaboration of new information and experiences associated with the observed conversation approach (Bohner \& Dickel, 2011; Stroebe, 2014). Another explanation for the changes we observed in the profiles could be that the students were 
urged to behave in particular ways by the work demands imposed upon them. If the required behaviours contradicted their attitudes, they may have been urged to modify their attitudes to avoid cognitive dissonance (rather than to try to change their clinical practice work; Haddock \& Maio, 2014). These possible attitude changes could be reflected in the changes within the profiles at the three time points as well as in the migration between the profiles at the different time points.

In comparing the three profiles and their development, it became apparent that the aspects of building a trustworthy interpersonal relationship and showing empathy increased in importance during the clinical electives. In particular, understanding the patients' perspectives became increasingly more important over time. The Q-methodology defines highly correlated profiles as comparable profiles (Watts \& Stenner, 2012; Weber et al., 2009). All profiles showed medium to high correlations at the different time points. Profiles \#1 and \#2 were highly correlated at the different time points, whereas profile \#3 showed a medium to high correlation with the other profiles. According to Watts and Stenner (2012), highly correlated profiles can be assumed to have high similarity. Also, the individual-toindividual correlations (which can be indicative of how the Q-sorts of the individual participants were comparable over time) showed medium to high degrees of correlation at the time points. However, these findings were not significant due to the small number of participants per profile. However, in Qmethodology, both qualitative and quantitative data are considered in the analyses. The quantitative data are just one part of the method to consider for interpretation, but the qualitative interpretation of the profiles also plays a role in the analyses. The participants as well as the factor structure were very stable over time, and this was especially evident in profile \#2. Students with this profile were already focusing on empathy and interpersonal relationships already at the beginning of their clinical electives. These findings are in line with those of Smith et al. (2017), who measured the development of empathy in the first three years of medical school in a longitudinal study by means of the Jefferson Scale of Physician Empathy (JSPE) and the Questionnaire of Cognitive and Affective Empathy (QCAE). The results of the QCAE showed an increase in taking the patients' perspectives and emotional contagion. However, empathy measured by JSPE showed a decrease during medical school. Another meta-analysis revealed that there was a measurable decline of empathy as assessed with the JSPE (Spatoula et al., 2019). While these contradictory issues have been discussed in medicine and medical education, there is currently no consensus on whether, how and why empathy changes over time (Spatoula et al., 2019). In our study, we could only make assumptions about the increased focus on empathy items in the development of all the profiles. The theory of attitude change posits that an attitude can change if one has had positive experiences with the attitude object. Students may have had good experiences in their clinical electives associated with interacting empathetically with patients and therefore may have been able to strengthen interpersonal relationships. Finally, increases in the importance of empathy and shared decision making were apparent in all profiles. Involving the patient in the decision-making process is regarded as important for the establishment of a successful doctor-patient relationship (Charles et al., 1997).

All profiles that emerged from our study exhibited good psychometric properties. The explained variances of the factor solutions for each time point were above $40 \%$ and therefore in a good range (Watts \& Stenner, 2012). In addition, the correlations between the profiles at the different time points were medium to high (Field, 2013). On this basis, we felt it was safe to interpret and elaborate on the development of the factors.

Nonetheless, some limitations regarding the interpretation of the results need to be addressed. Although our sample size was adequate for the Q-methodology approach (Watts \& Stenner, 2012), we could only study a convenience sample. The medical students participated voluntarily and were rewarded with book vouchers totalling 105 EUR if they participated at all three time points. The migration of students between the profiles was another limitation. As is apparent from our description of the results, there was a certain degree of change regarding the individual students that formed the attitude profiles at different points in time. We therefore argue that we could only trace the more general dynamics and trends occurring in our sample when describing how the profiles transformed over time. We also asked the students which statements they considered very important / important / less important in order to conduct a good medical interview with a patient. The aim of this question was to focus on 
the students' attitudes and not on their behaviour in doctor-patient dialogues. However, in accordance with the theory of attitude development, experiences of past behaviour also influence attitudes. Therefore, it is impossible to say exactly whether the students in our study predominantly referred to their attitudes, their previous behaviour or their perceived communication skills. Beyond these aspects, numerous individual-level dynamics emerged, which we cannot fully describe here.

Further issues, such as demographic properties and process variables, may emerge during the clinical electives as relevant predictors of individual transitions between profiles. In addition, our sample size was not large enough to find significant results or to interpret them accordingly. Moreover, it is evident that the Q-sort technique, just like any empirical method, is also affected by measurement error. One point worth noting here is that the structure of the Q-sort grid (cf. Figure 1) limits the degrees of freedom regarding the sorting of statements. This means that respondents could, for instance, not assign the highest level of importance to several items, even if this would perfectly reflect their personal viewpoints. Moreover, our study only provides evidence on how the medical students' attitude profiles developed over time. Future studies should focus on the question of how these profiles relate to students' actual behaviours in communication with patients.

To conclude, this study investigated the attitude profiles of medical students at the beginning of their electives and their development over time using Q-methodology. The profiles differed in regard to their emphasis on supporting shared decision making, establishing trustworthy relationships and structuring conversations. The importance of the empathetic aspect and shared decision making increased over time in all the profiles. Future research should investigate the interdependence between the attitudes and observed behaviours of the students as physicians in order to gain more information about the relationship between these variables in medical interviews.

\section{Key points}

- We investigate how senior medical students' attitudes towards doctor-patient communication develop through informal, workplace-based learning.

- The use of Q-methodology to assess these attitudes in a longitudinal perspective is an innovative methodological approach.

- Our study reveals three different attitude profiles that show different developmental patterns over time.

\section{Acknowledgements}

The study was part of the project $\mathrm{AKHOM}$, reference number: 01PK1501C and the project voLeA, reference number: 16DHB2133, both funded by the German Ministery of Education and Research.

\section{References}

Ajzen, I. (1991). The theory of planned behavior. Organizational Behavior and Human Decision Processes, 50(2), 179-211. https://doi.org/10.1016/0749-5978(91)90020-t

Ajzen, I., Fishbein, M., Lohmann, S., \& Albarracin, D. (2019). The influence of attitudes on behavior. In D. Albarracín \& B. T. Johnson (Eds.), The handbook of attitudes (pp. 197-255). Routledge.

Archer, R., Elder, W., Hustedde, C., Milam, A., \& Joyce, J. (2008). The theory of planned behaviour in medical education: A model for integrating professionalism training. Medical Education, 42(8), 771-777. https://doi.org/10.1111/j.1365-2923.2008.03130.x 
Berings, M. G. M. C., Poell, R. F., \& Simons, P. R.-J. (2005). Conceptualizing on-the-job learning styles. Human Resource Development Review, 4(4), 373-400.

https://doi.org/10.1177/1534484305281769

Blömeke, S., Gustafsson, J.-E., \& Shavelson, R. J. (2015). Beyond dichotomies: Competence viewed as a continuum. Zeitschrift Für Psychologie / Journal of Psychology, 223(1), 3-13. https://doi.org/10.1027/2151-2604/a000194

Bohner, G., \& Dickel, N. (2011). Attitudes and attitude change. Annual Review of Psychology, 62, 391-417. https://doi.org/10.1146/annurev.psych.121208.131609

Bombeke, K., Symons, L., Vermeire, E., Debaene, L., Schol, S., Winter, B. de, \& van Royen, P. (2012). Patient-centredness from education to practice: The 'lived' impact of communication skills training. Medical Teacher, 34(5), e338-48. https://doi.org/10.3109/0142159X.2012.670320

Bombeke, K., van Roosbroeck, S., Winter, B. de, Debaene, L., Schol, S., van Hal, G., \& van Royen, P. (2011). Medical students trained in communication skills show a decline in patient-centred attitudes: An observational study comparing two cohorts during clinical clerkships. Patient Education and Counseling, 84(3), 310-318. https://doi.org/10.1016/j.pec.2011.03.007

Brown, J. (2010). Transferring clinical communication skills from the classroom to the clinical environment: Perception of a group of medical students in the United Kingdom. Academic Medicine, 85, 1052-1059. https://doi.org/10.1097/ACM.0b013e3181dbf76f

Brown, S. R. (1996). Q methodology and qualitative research // Q Methodology and Qualitative Research. Qualitative Health Research, 6(4), 561-567. https://doi.org/10.1177/104973239600600408

Charles, C., Gafni, A., \& Whelan, T. (1997). Shared decision-making in the medical encounter: What does it mean? (or it takes at least two to tango). Social Science \& Medicine, 44(5), 681-692. https://doi.org/10.1016/S0277-9536(96)00221-3

Cross, R. M. (2005). Exploring attitudes: The case for Q methodology. Health Education Research, 20(2), 206-213. https://doi.org/10.1093/her/cyg121

Edmondson, A. (1999). Psychological safety and learning behavior in work teams. Administrative Science Quarterly, 44(2), 350. https://doi.org/10.2307/2666999

Epstein, R. M. (2007). Assessment in medical education. The New England Journal of Medicine, 356, 387-396. https://doi.org/10.1056/NEJMra054784

Epstein, R. M., \& Hundert, E. M. (2002). Defining and assessing professional competence. JAMA, 287(2), 226. https://doi.org/10.1001/jama.287.2.226

Epstein, R. M., \& Street, R. L. (2011). The values and value of patient-centered care. Annals of Family Medicine, 9(2), 100-103. https://doi.org/10.1370/afm.1239

Eraut, M. (2000). Non-formal learning and tacit knowledge in professional work. British Journal of Educational Psychology, 70(1), 113-136. https://doi.org/10.1348/000709900158001

Fallowfield, L., Jenkins, V., Farewell, V., Saul, J., Duffy, A., \& Eves, R. (2002). Efficacy of a cancer research UK communication skills training model for oncologists: A randomised controlled trial. The Lancet, 359(9307), 650-656. https://doi.org/10.1016/S0140-6736(02)07810-8

Fazio, R. H., \& Olsen, M. A. (2014). The MODE model: Attitude-behavior processes as a function of motivation and opportunity. In J. W. Sherman, B. Gawronski, \& Y. Trope (Eds.), Dual-Process Theories of the Social Mind (pp. 155-171). Guilford Publications.

Field, A. (2013). Discovering Statistics using IBM SPSS Statistics: And Sex and Drugs and Rock ' $n$ ' Roll (4 ${ }^{\text {th }}$ edition). MobileStudy. SAGE. 
Flocke, S. A., Miller, W. L., \& Crabtree, B. F. (2002). Relationship between physician practice style, patient satisfaction, and attributes of primary care. The Journal of Family Practice, 51(10).

Giroldi, E., Veldhuijzen, W., Geelen, K., Muris, J., Bareman, F., Bueving, H., van der Weijden, T., \& van der Vleuten, C. (2017). Developing skilled doctor-patient communication in the workplace: A qualitative study of the experiences of trainees and clinical supervisors. Advances in Health Sciences Education: Theory and Practice. Advance online publication. https://doi.org/10.1007/s10459-017-9765-2

Grassi, L., Giraldi, Z., Messina, E. G., Valle, E., \& Cartei, G. (2000). Physicians' attitudes to and problems with truth-telling to cancer patients. Support Care Cancer, 8, 40-45. https://doi.org/10.1007/s005209900067

Ha, J. F., Surg Anat, D., \& Longnecker, N. (2010). Doctor-patient communciation: a review. The Ochsner Journal, 10, 38-43.

Hackert, C., \& Braehler, G. (2007). FlashQ [Computer software]. http://www.hackert.biz/flashq/home/

Haddock, G., \& Maio, G. R. (2014). Einstellungen [Attitudes]. In K. Jonas, W. Stroebe, M. Hewstone, \& M. Reiss (Eds.), Springer-Lehrbuch. Sozialpsychologie (6th ed., pp. 197-229). Springer. https://doi.org/10.1007/978-3-642-41091-8_6

Hartig, J. (2008). Psychometric models for the assessment of competencies. In J. Hartig, E. Klieme, \& D. Leutner (Eds.), Assessment of Competencies in Educational Contexts (pp. 70-90). Hogrefe \& Huber.

Klooster, P. M. ten, Visser, M., \& Jong, M. D.T. de (2008). Comparing two image research instruments: The Q-sort method versus the Likert attitude questionnaire. Food Quality and Preference, 19(5), 511-518. https://doi.org/10.1016/j.foodqual.2008.02.007

Krupat, E., Rosenkranz, S. L., Yeager, C. M., Barnard, K., Putnam, S. M., \& Inui, T. S. (2000). The practice orientations of physicians and patients: the effect of doctor-patient congruence on satisfaction. Patient Education and Counseling, 39, 49-59. https://doi.org/10.1016/S07383991(99)00090-7

Kurtz, S., Silverman, J., \& Draper, J. (2016). Teaching and learning communication skills in medicine ( $2^{\text {nd }}$ ed.). CRC Press. http://gbv.eblib.com/patron/FullRecord.aspx?p=4711378

Kyndt, E., Dochy, F., \& Nijs, H. (2009). Learning conditions for non-formal and informal workplace learning. Journal of Workplace Learning, 21(5), 369-383. https://doi.org/10.1108/13665620910966785

Langewitz, W. (2012). Zur Erlernbarkeit der Arzt-Patienten-Kommunikation in der Medizinischen Ausbildung [Physician-patient communication in medical education: can it be learned?]. Bundesgesundheitsblatt, Gesundheitsforschung, Gesundheitsschutz, 55(9), 1176-1182. https://doi.org/10.1007/s00103-012-1533-0

Levinson, W., Lesser, C. S., \& Epstein, R. M. (2010). Developing physician communication skills for patient-centered care. Health Affairs (Project Hope), 29(7), 1310-1318. https://doi.org/10.1377/hlthaff.2009.0450

Locatelli, C., Piselli, P., Cicerchia, M., \& Repetto, L. (2013). Physicians' age and sex influence breaking bad news to elderly cancer patients. Beliefs and practices of 50 Italian oncologists: The G.I.O.Ger study. Psycho-Oncology, 22(5), 1112-1119. https://doi.org/10.1002/pon.3110

Loh, A., \& Simon, D. (2009). Gemeinsame Entscheidungsfindung von Arzt und Patient: Das Konzept des ,shared decision making“ [Shared decision making between doctor and patient: The concept of "shared decision making"]. In T. Langer \& M. W. Schnell (Eds.), Das Arzt-Patient Patient-Arzt Gespräch (pp. 143-152). Hans Marseille Verlag GmbH. 
Manuti, A., Pastore, S., Scardigno, A. F., Giancaspro, M. L., \& Morciano, D. (2015). Formal and informal learning in the workplace: A research review. International Journal of Training and Development, 19(1), 1-17. https://doi.org/10.1111/ijtd.12044

McHugh, N., Baker, R., Biosca, O., Ibrahim, F., \& Donaldson, C. (2019). Who knows best? A Q methodology study to explore perspectives of professional stakeholders and community participants on health in low-income communities. BMC Health Services Research, 19(1), 35. https://doi.org/10.1186/s12913-019-3884-9

McHugh, N., van Exel, J., Mason, H., Godwin, J., Collins, M., Donaldson, C., \& Baker, R. (2018). Are life-extending treatments for terminal illnesses a special case? Exploring choices and societal viewpoints. Social Science \& Medicine (1982), 198, 61-69. https://doi.org/10.1016/j.socscimed.2017.12.019

Mehay, R., \& Burns, R. (2009). Miller's pyramid of clinical competence (1990). https://www.essentialgptrainingbook.com/ch29/

Muddiman, E., Bullock, A. D., Hampton, J. M., Allery, L., MacDonald, J., Webb, K. L., \& Pugsley, L. (2019). Disciplinary boundaries and integrating care: Using Q-methodology to understand trainee views on being a good doctor. BMC Medical Education, 19(1), 59. https://doi.org/10.1186/s12909019-1493-2

Müller, F. H., \& Kals, E. (2004). Q-Sort technique and Q-methodology: Innovative methods for examining attitudes and opinions. Forum Qualitative Sozialforschung / Forum: Qualitative Social Research, 5(2). http://www.qualitative-research.net/index.php/fqs/article/download/600/1302

Petty, R. E., Tormala, Z. L., Briñol, P., \& Jarvis, W. B. G. (2006). Implicit ambivalence from attitude change: An exploration of the PAST model. Journal of Personality and Social Psychology, 90(1), 21-41. https://doi.org/10.1037/0022-3514.90.1.21

Rees, C., Sheard, C., \& Davies, S. (2002). The development of a scale to measure medical students' attitudes towards communication skills learning: the Communication Skills Attitude Scale (CSAS). Medical Education, 36(141-147). https://doi.org/10.1046/j.1365-2923.2002.01072.x

Rider, E. A. (2010). Interpersonal and communication skills. In E. A. Rider \& R. H. Nawotniak (Eds.), A Practical Guide to Teaching and Assessing the ACGME Core competencies (2 ${ }^{\text {nd }}$ ed., pp. 1-137). HCPro, Inc.

Rider, E. A., \& Nawotniak, R. H. (Eds.). (2010). A Practical Guide to Teaching and Assessing the $A C G M E$ Core competencies ( $2^{\text {nd }}$ edition). HCPro, Inc.

Roter, D., Stewart, M., Putnam, S. M., Lipkin, M., Stiles, W., \& Inui, T. S. (1997). Communication patterns of primary care physicians. JAMA, 277, 350-356. https://doi.org/10.1001/jama.1997.03540280088045

Schick, K., Berberat, P. O., Kadmon, M., Harendza, S., \& Gartmeier, M. (2019). German Language Adaptation of the Kalamazoo Communication Skills Assessment Form (KCSAF): A multi-method study of two cohorts of medical students. Zeitschrift Für Pädagogische Psychologie, 33(2), 135147. https://doi.org/10.1024/1010-0652/a000241

Smith, K. E., Norman, G. J., \& Decety, J. (2017). The complexity of empathy during medical school training: Evidence for positive changes. Medical Education, 51(11), 1146-1159. https://doi.org/10.1111/medu.13398

Spatoula, V., Panagopoulou, E., \& Montgomery, A. (2019). Does empathy change during undergraduate medical education? - A meta-analysis. Medical Teacher, 1-10. https://doi.org/10.1080/0142159X.2019.1584275

Stephenson, W. (1936). The inverted factor technique. British Journal of Psychology, 26, 344-361. https://doi.org/10.1111/j.2044-8295.1936.tb00803.x 
Strack, F., \& Deutsch, R. (2004). Reflective and Impulsive Determinants of Social Behavior. Personality and Social Psychology Review, 8(3), 220-247. https://doi.org/10.1207/s15327957pspr0803_1

Stroebe, W. (2014). Strategien zur Einstellungs- und Verhaltensänderung [Attitude and behavior change strategies]. In K. Jonas, W. Stroebe, M. Hewstone, \& M. Reiss (Eds.), Springer-Lehrbuch. Sozialpsychologie (6th ed., pp. 231-268). Springer.

Tynjälä, P. (2008). Perspectives into learning at the workplace. Educational Research Review, 3(2), 130-154. https://doi.org/10.1016/j.edurev.2007.12.001

Watts, S., \& Stenner, P. (2005). Doing Q methodology: Theory, method and interpretation. Qualitative Research in Psychology, 2(1), 67-91. https://doi.org/10.1191/1478088705qp022oa

Watts, S., \& Stenner, P. (2012). Doing $Q$ methodological research: Theory, method and interpretation. SAGE.

Weber, T., Danielson, S., \& Tuler, S. (2009). Using $Q$ method to reveal social perspectives in environmental research. Greenfield, MA. Social and Enviromental Research Institute. www.serius.org/pubs/Qprimer.pdf

Woloschuk, W., Harasym, P. H., \& Temple, W. (2004). Attitude change during medical school: A cohort study. Medical Education, 38(5), 522-534. https://doi.org/10.1046/j.13652929.2004.01820.x

Zabala, A. (2018). Package "qmethod" (Version 1.5.4) [Computer software]. https://cran.rproject.org/web/packages/qmethod/qmethod.pdf 